
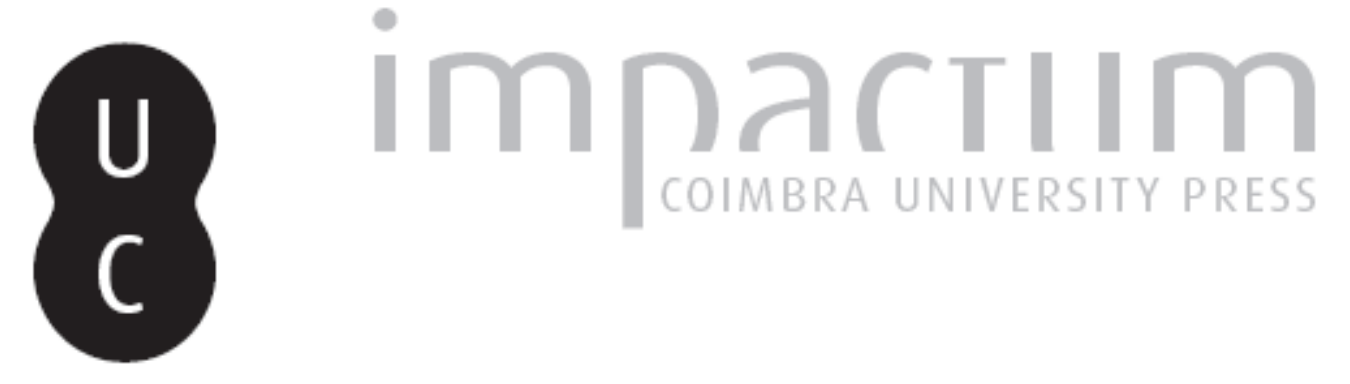

\title{
Vulnerabilidade escolar frente a desastres no Brasil
}

Autor(es): $\quad$ Marchezini, Victor; Muñoz, Viviana Aguilar; Trajber, Rachel

Publicado por: Imprensa da Universidade de Coimbra

URL persistente:

URl:http://hdl.handle.net/10316.2/44213

DOI:

DOI:https://doi.org/10.14195/1647-7723_25-2_13

Accessed : $\quad$ 26-Apr-2023 06:28:04

A navegação consulta e descarregamento dos títulos inseridos nas Bibliotecas Digitais UC Digitalis, UC Pombalina e UC Impactum, pressupõem a aceitação plena e sem reservas dos Termos e Condições de Uso destas Bibliotecas Digitais, disponíveis em https://digitalis.uc.pt/pt-pt/termos.

Conforme exposto nos referidos Termos e Condições de Uso, o descarregamento de títulos de acesso restrito requer uma licença válida de autorização devendo o utilizador aceder ao(s) documento(s) a partir de um endereço de IP da instituição detentora da supramencionada licença.

Ao utilizador é apenas permitido o descarregamento para uso pessoal, pelo que o emprego do(s) título(s) descarregado(s) para outro fim, designadamente comercial, carece de autorização do respetivo autor ou editor da obra.

Na medida em que todas as obras da UC Digitalis se encontram protegidas pelo Código do Direito de Autor e Direitos Conexos e demais legislação aplicável, toda a cópia, parcial ou total, deste documento, nos casos em que é legalmente admitida, deverá conter ou fazer-se acompanhar por este aviso.

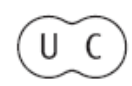




\section{VULNERABILIDADE ESCOLAR FRENTE A DESASTRES NO BRASIL*}

SCHOOL VULNERABILITY TO DISASTERS IN BRAZIL

Victor Marchezini

Centro Nacional de Monitoramento e Alertas de Desastres Naturais - CEMADEN (Brasil) ORCID 0000-0002-1974-0960 victor.marchezini@cemaden.gov.br

Viviana Aguilar Muñoz

Centro Nacional de Monitoramento e Alertas de Desastres Naturais - CEMADEN (Brasil) ORCID 0000-0002-2899-8082 viviana.munoz@cemaden.gov.br

Rachel Trajber

Centro Nacional de Monitoramento e Alertas de Desastres Naturais - CEMADEN (Brasil) ORCID 0000-0002-3270-2352 rachel.trajber@cemaden.gov.br

\section{RESUMO}

Este trabalho teve por objetivo apresentar um diagnóstico da situação de vulnerabilidade das escolas perante desastres socioambientais no Brasil. Foi possível identificar cinco tipologias principais de impacto: sobre a integridade física das pessoas, sobre a rotina da escola por mudança de uso e ocupação em situação de desastre, sobre a estrutura física do edifício, sobre os materiais e equipamentos escolares e sobre o exercício educativo propriamente dito. Por fim, ressalta-se que os formuladores de políticas e os gestores da área de gestão de riscos e de desastres precisam envolver o setor educativo na formulação de políticas para reduzir sua própria vulnerabilidade.

Palavras-chave: Desastres, vulnerabilidade, escolas, educação, redução do risco.

\section{ABSTRACT}

This study set out to analyze some aspects of the vulnerability of schools to socio-environmental disasters in Brazil. The study identified five main impacts in the educational sector: on the physical safety of students, teachers and other school workers; on the routine of schools due to their use as temporary shelter for people affected by disasters; on the physical structure of school buildings damaged in an event; on material and equipment that may be damaged; on the very education of students. We highlight the fact that policymakers and practitioners in the fields of risk management and disaster management need to involve the education sector in the formulation of policies to reduce that sector's vulnerability.

Keywords: Disasters, vulnerability, schools, education, risk reduction.

\footnotetext{
* O texto deste artigo corresponde a uma comunicação apresentada no IV Congresso Internacional de Riscos, tendo sido submetido em 31-07-2017, sujeito a revisão por pares a 19-10-2017 e aceite para publicação em 18-12-2017. Este artigo é parte integrante da Revista Territorium, n. ${ }^{\circ} 25$ (II), 2018, ${ }^{\circ}$ RIscos, ISSN: 0872-8941.
} 


\section{Introdução}

Os desastres socioambientais vivenciados no Brasil nos anos recentes mobilizaram uma nova agenda política e científica no tema, sobretudo em razão da catástrofe da região serrana do Rio de Janeiro em 2011, com mais de R\$ 4,78 bilhões em prejuízos materiais, 905 mortes, 300 desaparecidos e mais de 300 mil afetados (BANCO MUNDIAL, 2012a).

Essas catástrofes são o resultado de um processo social sobre o território cuja vulnerabilidade é revelada diante de eventos naturais como secas e chuvas, de falhas tecnológicas como o rompimento de barragens, ou a combinação de diferentes eventos em cadeia que têm sido intensificados pela influência antrópica (Valencio, 2012; Oliver-Smith et al., 2016; 2017). Em outras palavras, os desastres não são naturais (O'Keefe et al., 1976; Wisner et al., 2004). Sobre esse aspecto, se pensarmos para além do "dia do desastre", o perfil de desastres no país revela um quadro de crise estrutural, silente e crônica (Valencio, 2012), uma vez que no período 2003-2014 foram emitidas 23.422 portarias de situação de emergência (S.E.) e estado de calamidade pública (E.C.P.) em um conjunto de 5.570 municípios (média de 1.951 portarias ao ano). Como conhecer esses riscos de desastres e buscar formas de reduzilos? Estas são questões que desafiam a comunidade científica internacional e determinam de certa forma as metas e prioridades de tratados globais que tratam desses assuntos.

Os riscos são situações complexas, fenômenos multifatoriais que podem ser definidos a partir da relação entre ameaça (s), vulnerabilidade (s) e capacidade (s). A ameaça pode ser de origem física (por exemplo, terremotos, furacões, tsunamis, secas ou chuvas), biológica (por exemplo, epidemias virais) ou tecnológica (por exemplo, irradiação radioativa ou rompimento de barragens). Já a vulnerabilidade é conceituada, em termos gerais, como o potencial de sofrer danos (Romero e Maskrey, 1993; Wisner, 2016). Mas essa componente do risco não é tão simples de avaliar, pois envolve questões sociais tão complexas, quando não subjetivas, como a política, a cultura, a economia ou a educação.

Segundo a Unicef (2012), entre os grupos que apresentam maior vulnerabilidade a desastres, inserem-se crianças e adolescentes. Registros históricos globais indicam que nessa faixa etária se encontra aproximadamente 50\% dos atingidos em desastres. Em particular preocupa a situação das escolas: a gravidade deste problema no setor educativo pode ser ilustrada com numerosos casos de escolas que foram atingidas por fenômenos desse tipo ao redor do mundo. No Quênia, por exemplo, durante as inundações de dezembro de 2006, mais de 30 escolas foram destruídas no distrito de Nyando (Ochola et al.,
2010). Mas esta situação também afeta países ricos; na Inglaterra, por exemplo, várias escolas da cidade de Hull foram surpreendidas por uma chuva torrencial seguida de inundação brusca, em 2007. Neste caso já havia conhecimento do alto risco de inundação para essas escolas, mas a comunidade escolar, composta por alunos, professores e funcionários, não estava preparada para uma situação de desastre; isto devido principalmente à política institucional dos órgãos de proteção e defesa civil, que subestimava a exposição e a vulnerabilidade das escolas e desconsiderava o envolvimento da comunidade escolar em ações de prevenção (Convery et al., 2014). O Brasil não está imune a essa situação. Em 2008, 270 escolas foram inundadas no Vale do Itajaí, Santa Catarina (Banco Mundial, 2012b); em 2010, durante as inundações no Estado Alagoas, 115 escolas ficaram danificadas; na tragédia da Região Serrana de Rio de Janeiro (2011), 25 escolas foram atingidas por inundações, deslizamentos e enxurradas (Assembleia Legislativa do Estado do Rio de Janeiro - ALERJ, 2011).

A construção de escolas inseguras (vulnerabilidade estrutural)emáreas sujeitas a inundações, deslizamentos, terremotos maximiza os riscos da comunidade escolar. Por outro lado, boa parte de crianças e adolescentes (principalmente de setores carentes) são altamente sujeitos à vulnerabilidade social, como a derivada do tráfico de drogas, da guerra civil, da exclusão, do descaso pela educação ou da ausência de oportunidades. Situações de desastres, como as apresentadas nos exemplos de Quênia, Inglaterra e Brasil, podem ser explicadas, em parte, pelo alto grau de vulnerabilidade física e social do sistema educativo, pois essas condições fragilizam as capacidades individuais e coletivas para responder às crises e superá-las, tanto no ensino fundamental quanto no ensino médio (Unicef, 2012). É muito comum que as políticas de prevenção e redução do risco de desastres negligenciem ou considerem de forma apenas superficial soluções efetivas para este problema; da mesma forma, faltam pesquisas cientificas nesta área do conhecimento (Anderson, 2005, Peek, 2008), além da falta de informação e de treinamento da comunidade escolar para lidar com situações de risco de desastres.

Nesse contexto, o objetivo deste artigo é analisar as diversas dimensões da vulnerabilidade escolar, no ensino fundamental e médio, frente a situações de desastre no Brasil. Na primeira parte do documento apresenta-se um arcabouço conceitual e discutem-se as dimensões do conceito de vulnerabilidade. Em seguida é feito um diagnóstico da situação de vulnerabilidade das escolas a partir de registros históricos de ocorrências de desastres no país e da normatividade institucional brasileira em gestão de risco de desastres. Por fim, apresentam-se algumas recomendações para subsidiar políticas públicas da gestão de risco de desastres no sistema educativo brasileiro. 


\section{Material e métodos}

Este estudo teve como base a pesquisa bibliográfica e a pesquisa documental. A pesquisa bibliográfica teve como objetivo apresentar uma base conceitual consistente para melhor compreender o conceito de vulnerabilidade, no contexto de pesquisa em desastres, assim como suas interfaces com a temática de escolas e população infanto-juvenil.

A pesquisa documental avaliou os danos decorrentes do impacto de fenômenos naturais nas escolas do Brasil. Para isso, foram analisados documentos do Ministério da Educação - Fundo Nacional de Desenvolvimento da Educação (MEC/FNDE) e os trabalhos de escolas participantes da IV Conferência Nacional Infantojuvenil pelo Meio Ambiente -, bem como formulários de Avaliação de Danos (AVADAN) e de informações sobre desastres (FIDE), da Secretaria Nacional de Defesa Civil. Adicionalmente, para complementar essa análise, foi realizada uma pesquisa na web sobre impactos de desastres em escolas do Brasil, entre 01/01/2012 e $31 / 12 / 2015$ - período em que foi estabelecido, sem a participação do setor educativo, o Plano Nacional de Gestão de Riscos e Resposta a Desastres (PNGRD). As palavras-chave utilizadas no buscador Google foram: "escola inundada", "escola alagada", "enchente em escola", “deslizamento" e "escola". Utilizou-se essa fonte de consulta como uma alternativa para encontrar exemplos específicos de impactos e perdas em escolas, que poderiam não ter sido enquadradas como desastres e consequentemente não estariam registradas nas fontes oficiais. Os dados históricos de ocorrência de eventos geológicos ou hidrológicos com impactos sobre escolas não são fáceis de serem coletados, pois ainda não existe a cultura institucional de registro sistemático dessas ocorrências e nem bancos de dados oficiais e de cobertura no âmbito nacional que os possam proporcionar. Embora registros jornalísticos não constituam um dado oficial para subsidiar a pesquisa criteriosa sobre a vulnerabilidade escolar, muitas vezes este é o único disponível para esse propósito, e por isso deve ser aproveitado.

Por fim, também foi utilizada uma base de dados do Instituto Nacional de Estudos e Pesquisas Educacionais Anísio Teixeira (INEP), com informações diversas das escolas registradas nessa instituição. As análises apresentadas neste artigo têm uma forte componente espacial que inclui a localização geográfica das escolas, sua distribuição no território nacional e sua relação com as áreas de risco oficialmente mapeadas no país, assim como a composição de uma base de dados em Sistemas de Informação Geográfica (SIG). Para o georreferenciamento das escolas e sua incorporação no SIG utilizaram-se as coordenadas (latitude, longitude) obtidas da base de dados INEP. Aspectos da exposição escolar a eventos geológicos e hidrológicos das escolas no Brasil foram observados a partir do cruzamento do mapa da distribuição das escolas, preparado para este trabalho, com os mapas de áreas de risco produzidos pelo Serviço Geológico do Brasil (CPRM) no período de janeiro de 2012 a dezembro de 2015.

\section{Arcabouço conceitual: tipologias da vulnerabilidade}

O conceito de vulnerabilidade tem várias definições, abordagens quantitativas e qualitativas e métodos de análise (Wisner, 2016; Oliver-Smith et al., 2016). Uma dessas abordagens sugere a compreensão do conceito a partir de diferentes dimensões: natural, física, econômica, social, política, tecnológica, ideológica, cultural, educacional, ecológica e institucional (Wilches-Chaux, 1993; Lavell, 1993; Marchezini, 2015; Marchezini et al., 2017). Essa abordagem facilita a análise dos indicadores macrossociais de intensificação ou redução da vulnerabilidade, e consequentemente contribui com o gerenciamento dos riscos numa sociedade. Na TABELA I são apresentados conceitos gerais das tipologias da vulnerabilidade desse modelo analítico, mas, para fins de discussão e análise, serão acrescentados por extenso maiores detalhes de algumas tipologias, especificamente, vulnerabilidade natural, física, social, institucional e educacional:

- Vulnerabilidade natural. Está relacionada com as condicionantes ambientais para o desenvolvimento da vida como, por exemplo, a oferta natural de água. Esta vulnerabilidade pode ser reduzida se houver recursos (econômicos, humanos) e vontade (política/empresarial) para investir em soluções de prevenção de crises hídricas. A falta de água potável pode ser solucionada com a aplicação de medidas estruturais cujas estratégias cabem à engenharia. Quando a diminuição ou a deterioração de um recurso natural não renovável afeta unidades territoriais vizinhas (por exemplo, países, estados ou cidades vizinhas), o processo de fragilização social e política pode ser intensificado à medida que venham a ocorrer disputas pela exploração ou conservação desse recurso.

- Vulnerabilidade fisíca. Está relacionada com dois aspectos principais: 1) a localização de elementos antrópicos em áreas suscetíveis, por exemplo, no sopé de cicatrizes de deslizamentos ou sobre várzeas. Este aspecto da vulnerabilidade física está estreitamente vinculado com o conceito de exposição, e 2) a condição estrutural das edificações (por exemplo, colunas, vigas, fundações), resistência dos materiais constitutivos (por exemplo, taipa, madeira ou concreto) e eficiência do projeto arquitetônico (largura de corredores, existência de janelas e portas) para absorver os impactos causados por fenômenos naturais. Em regiões sismicamente 
ativas, por exemplo, os projetos de obras civis devem considerar a normativa de construções sismo-resistentes para diminuir a vulnerabilidade estrutural desses empreendimentos.

- Vulnerabilidade social. Esta tipologia de vulnerabilidade está diretamente relacionada com aspectos da organização social, que obedecem a especificidades de proteção da integridade física, mental e emocional dos grupos mais fragilizados (crianças, idosos, pessoas com dificuldade de locomoção, gestantes, populações em situação de rua, pessoas com doenças crônicas). É relevante caracterizar as especificidades da vulnerabilidade desses grupos sob pelo menos três aspectos: 1) conferir visibilidade aos problemas emergentes nesse contexto particular; 2) interpretar essas dificuldades particulares e refletir sobre a ética e práticas sociopolíticas necessárias ao gerenciamento de riscos; e 3) propiciar a criação de novos valores e práticas a serem implementadas quando as relações entre os indivíduos e coletivos da sociedade estiverem desgastadas (Valencio et al., 2006).

- Vulnerabilidade institucional. Está relacionada com a fragilidade das instituições governamentais, nos diversos níveis de governo (nacional, estadual, municipal etc.). Esta é frequentemente pautada pela corrupção devido a práticas que instrumentalizam as instituições para auferir benefícios particulares a partir dos recursos públicos. A vulnerabilidade institucional também está relacionada com a gestão, e depende da rigidez ou flexibilidade das instituições governamentais diante da resolução de problemas socioambientais, e da importância que é atribuída a questões como a reavaliação de práticas de prevenção e conservação ou criação de políticas públicas destinadas a enfrentar os desafios da gestão de risco de desastres. Nos processos de criação de políticas públicas e tomada decisão, o grande desafio para as instituições é abdicar de critérios políticos de curto prazo que favorecem indivíduos e optar por critérios que favoreçam soluções de longo prazo e garantam o benefício coletivo.

- Vulnerabilidade educacional. A vulnerabilidade educacional refere-se ao grau de fragilidade das comunidades escolares (estudantes, professores, alunos, funcionários, moradores do entorno, bens tangíveis e intangíveis da escola) em função do contexto ambiental onde se encontram inseridas, dos tipos de ameaças às quais estão expostas, e da somatória das outras vulnerabilidades mencionadas na TABELA I, e que afetam tanto as escolas quanto a sociedade como um todo.

Dentre os grupos mais vulneráveis da sociedade destacam-se crianças e adolescentes em idade escolar, especialmente por estarem, na visão de Pavan (2009), sujeitos a pelo menos três tipos de vulnerabilidade 1) Vulnerabilidade física, no sentido de que estes geralmente dispõem de menos força e destreza para se proteger diante de uma situação de perigo (por exemplo, uma enxurrada). Peek (2008) afirma que esta limitação pode aumentar seu grau de fragilidade ante situações de desastres no curto prazo, como grande propensão

TABELA I - Tipologias da vulnerabilidade.

TABLE I - Dimensions of vulnerability.

\begin{tabular}{|c|c|}
\hline Tipo & Definição \\
\hline Natural & Intrínseca aos próprios limites ambientais da vida. \\
\hline Física & $\begin{array}{l}\text { Localização em zonas suscetíveis a ameaças naturais e/ou deficiência das estruturas físicas para absorver os impactos } \\
\text { desses fenômenos. }\end{array}$ \\
\hline Ecológica & Relacionada à perspectiva ambiental adotada pelos modelos de desenvolvimento. \\
\hline Econômica & Dependência econômica, ausência de investimento, falta de diversificação da base econômica, desigualdade social, pobreza. \\
\hline Social & Baixo grau de organização e coesão social para prevenir, mitigar e responder a situações de desastre. \\
\hline Política & Alto grau de centralização na tomada de decisão e na organização governamental. \\
\hline Tecnológica & Técnicas inadequadas de construção de edifícios e de infraestrutura. \\
\hline Ideológica & Relacionada às representações sobre o mundo e sobre o meio-ambiente. Por exemplo, passividade e fatalismo. \\
\hline Cultural & $\begin{array}{l}\text { Percepções próprias e influência dos meios de comunicação na percepção do meio ambiente e dos riscos de desastres, } \\
\text { muitas vezes através de imagens estereotipadas. }\end{array}$ \\
\hline Institucional & $\begin{array}{l}\text { Refletida, por exemplo, na obsolescência e rigidez das instituições, na prevalência de decisões políticas sobre critérios } \\
\text { técnicos e científicos e no predomínio de critérios personalistas na tomada de decisão. }\end{array}$ \\
\hline Educacional & $\begin{array}{l}\text { Ausência de programas de educação que incluam no seu currículo elementos conceituais e conhecimento sobre risco de } \\
\text { desastres; grau de preparação da população para enfrentar situações de desastre. }\end{array}$ \\
\hline
\end{tabular}


a sofrer os efeitos imediatos (mortes, ferimentos, doenças e abusos), e de longo prazo sobre suas rotinas, como, por exemplo, a interrupção das suas atividades escolares por causa da interdição do prédio escolar; 2) Vulnerabilidade cognitiva, uma vez que geralmente não têm experiências prévias que ajudem a criar estratégias de proteção em situações de insegurança; e 3) Vulnerabilidade emocional/psíquica, visto que crianças precisam de máxima proteção emocional em situações que demandam controle e calma para pensar e agir de forma adequada.

Nesse contexto, e considerando que as escolas são lugares onde se concentram grande quantidade de crianças e adolescentes, e que estes passam a maior parte do seu tempo nas escolas, é importante que os organismos responsáveis pela gestão pública e territorial criem estrategias para reduzir a vulnerabilidade educacional, pela incorporação de medidas estruturais (atenuação da vulnerabilidade física da escola) e não estruturais (por exemplo, programas educacionais que incluam o tema de prevenção de risco de desastres no currículo) nas políticas governamentais de gestão de riscos de desastres.

\section{Diagnóstico da situação de vulnerabilidade escolar frente a desastres no Brasil}

\section{Distribuição geográfica e exposição das escolas}

Para avaliar uma das dimensões da situação de vulnerabilidade física das escolas no Brasil, este trabalho realizou um diagnóstico de exposição de prédios escolares a ameaças hidrológicas (inundação, enxurrada, alagamento) e geológicas (deslizamentos). Efetuou-se um cruzamento em sistemas de informação geográfica (SIG) do mapeamento de escolas (representadas por pontos) e do mapeamento de áreas de risco (representados por polígonos). Todos esses mapeamentos estão georreferenciados e são do ano 2012. Para exemplificar o cruzamento, apresenta-se um detalhe da cidade de Belo Horizonte, na fig. 1.

Os dados de escolas correspondem ao levantamento anual de dados escolares do Brasil, Censo Escolar e Censo da Educação Superior, disponibilizados em planilha de atributos pelo Instituto Nacional de Estudos e Pesquisas Educacionais Anísio Teixeira (INEP, 2012). Para este trabalho, as escolas foram mapeadas a partir dos atributos de localização ("latitude, longitude”) registrados na planilha. O banco de dados conta com 125.321 registros de escolas de ensino fundamental e médio, sendo que 100.467 deles (80\%) são escolas da rede pública e o restante faz parte da rede privada. As áreas de risco foram mapeadas pelo Serviço Geológico do Brasil (CPRM, 2012), unicamente para os 957 municípios atualmente monitorados pelo Centro Nacional de Monitoramento e Alerta de Desastres Naturais (Cemaden). O cruzamento de dados esteve então restrito a estes municípios, que representam 17\% dos existentes no Brasil (atualmente são 5.570 municípios) (fig. 2).

Como resultado desse cruzamento cartográfico nos municípios monitorados pelo Cemaden, identificaramse 2443 escolas em área de risco: 729 escolas em área de risco hidrológico (ARH), sendo 533 públicas e 196 privadas, e 1714 escolas em área de risco geológico (ARG), sendo 1265 públicas e 449 privadas. Novos estudos poderão explicar a razão de se ter um maior número de escolas em ARG. É provável que este seja um indicativo de limitações do mapeamento atual disponível de ARH com cobertura nacional.

Um dos atributos do mapeamento das áreas de risco é o número de pessoas expostas; a partir desse dado, e uma vez que foram identificados os polígonos de risco onde se localizam escolas (pelo cruzamento

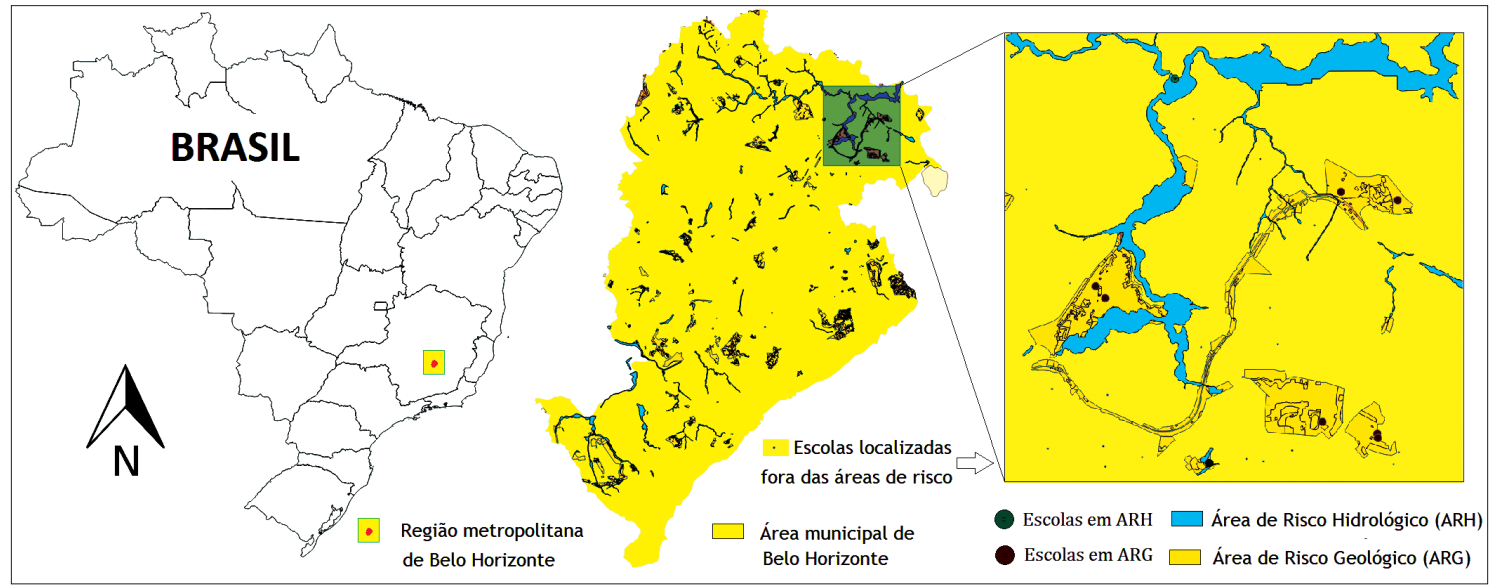

Fig. 1 - Recorte do mapeamento de áreas de risco e escolas, Belo Horizonte - Minas Gerais, que exemplifica em um detalhe o resultado do cruzamento em SIG desses mapas.

Fig. 1 - Example of risk areas and school mapping of Belo Horizonte town, Minas Gerais state, Brazil, which shows a detail the result of the GIS intersection of these maps. 


\section{BRASIL}

A. Municípios monitorados pelo CEMADEN

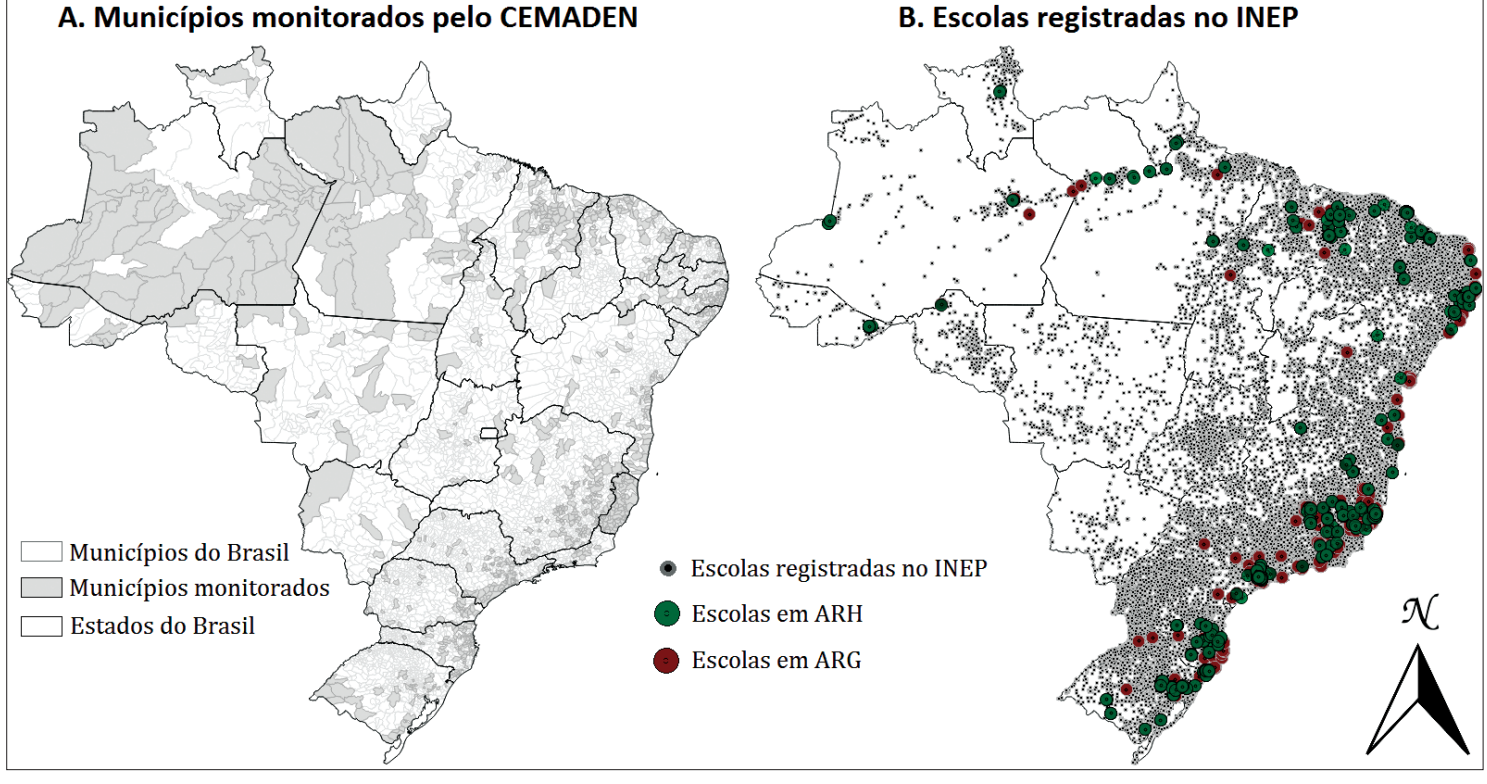

Fig. 2 - Localização de municípios monitorados pelo Cemaden nos diferentes estados brasileiros (mapa da esquerda) e distribuição das escolas registradas no banco de dados do INEP (mapa da direita); as escolas identificadas em área de risco hidrológico (ARH) e geológico (ARG) são aquelas dos 957 municípios monitorados pelo Cemaden. 0 número de escolas expostas irá aumentar na medida em que outros municípios passarem a ser monitorados e que o mapeamento de áreas de risco for atualizado.

Fig. 2 - Municipalities monitored by Cemaden (left-hand map) and distribution of schools entered in the INEP database (righthand map). It should be noted that schools in hydrological (ARH) and geological risk-prone areas (ARG) were only identified in 957 municipalities monitored by Cemaden. The current figures for exposed schools will increase very soon as other municipalities will be monitored and the risk mapping will be updated.

cartográfico), observou-se que há aproximadamente três milhões de pessoas, vinculadas a esses polígonos, que podem ser afetadas por inundações ou deslizamentos. A estimativa de escolas e pessoas expostas tende a ser maior, considerando que: (i) os números apresentados neste documento se referem somente aos municípios monitorados pelo Cemaden (17\% do total de municípios brasileiros); (ii) os mapeamentos de ARH no Brasil devem ser melhorados; e (iii) na base de dados do INEP podem não estar registradas todas as escolas do país. Esta análise espacial é somente um diagnóstico preliminar e não exaustivo, com o qual se pretende chamar a atenção e levantar questões sobre a exposição de escolas a inundações, alagamentos e deslizamentos, conhecendo, ainda que preliminarmente, os possíveis riscos de desastre que sistema educacional brasileiro está sujeito. Estudos futuros poderão se dedicar a analisar esses riscos em diferentes escalas (local, regional, estadual), bem como analisar como a dinâmica do risco tem ocorrido em escala nacional.

Na fig. 3 apresenta-se a distribuição numérica de escolas registradas no INEP e localizadas em área de risco geológico e hidrológico. Os Estados com maior exposição de escolas à ameaça geológica são Minas Gerais (MG), Pernambuco (PE), Bahia (BA) e Santa Catarina (SC). A maior exposição de escolas à ameaça hidrológica ocorre nos Estados de São Paulo (SP), Santa Catarina (SC) e Rio Grande do Sul (RS). Nota-se ainda que na região Norte se registra o menor número de escolas expostas às duas tipologias de ameaça, isto pode ser devido a: 1) existirem menor número de ARG pela topografia plana dessa região; 2) existirem menos escolas registradas no INEP; ou, ainda, 3) a densidade de escolas (número de escolas por $\mathrm{km}^{2}$ ) nessa região ser baixa.

A exposição é um elemento importante para caracterizar a vulnerabilidade escolar. Os dados apresentados nas fig.s 1 e 2 representam a exposição de escolas a eventos geológicos e hidrológicos em municípios com mapeamento oficial de áreas de risco no Brasil. Além desta informação, também interessa observar a distribuição espacial e numérica de ocorrências de desastres que têm impactado as escolas, pois sua análise pode revelar indicadores da vulnerabilidade escolar.

Dados históricos de ocorrência de desastres com impacto nas escolas

A fig. 4 é uma síntese sobre eventos naturais que afetaram escolas no Brasil entre 01 de janeiro de 2012 e 31 de dezembro de 2015, construída a partir de 86 casos coletados de diversas fontes jornalísticas e da internet. Nota-se que os eventos hidrológicos (inundação 


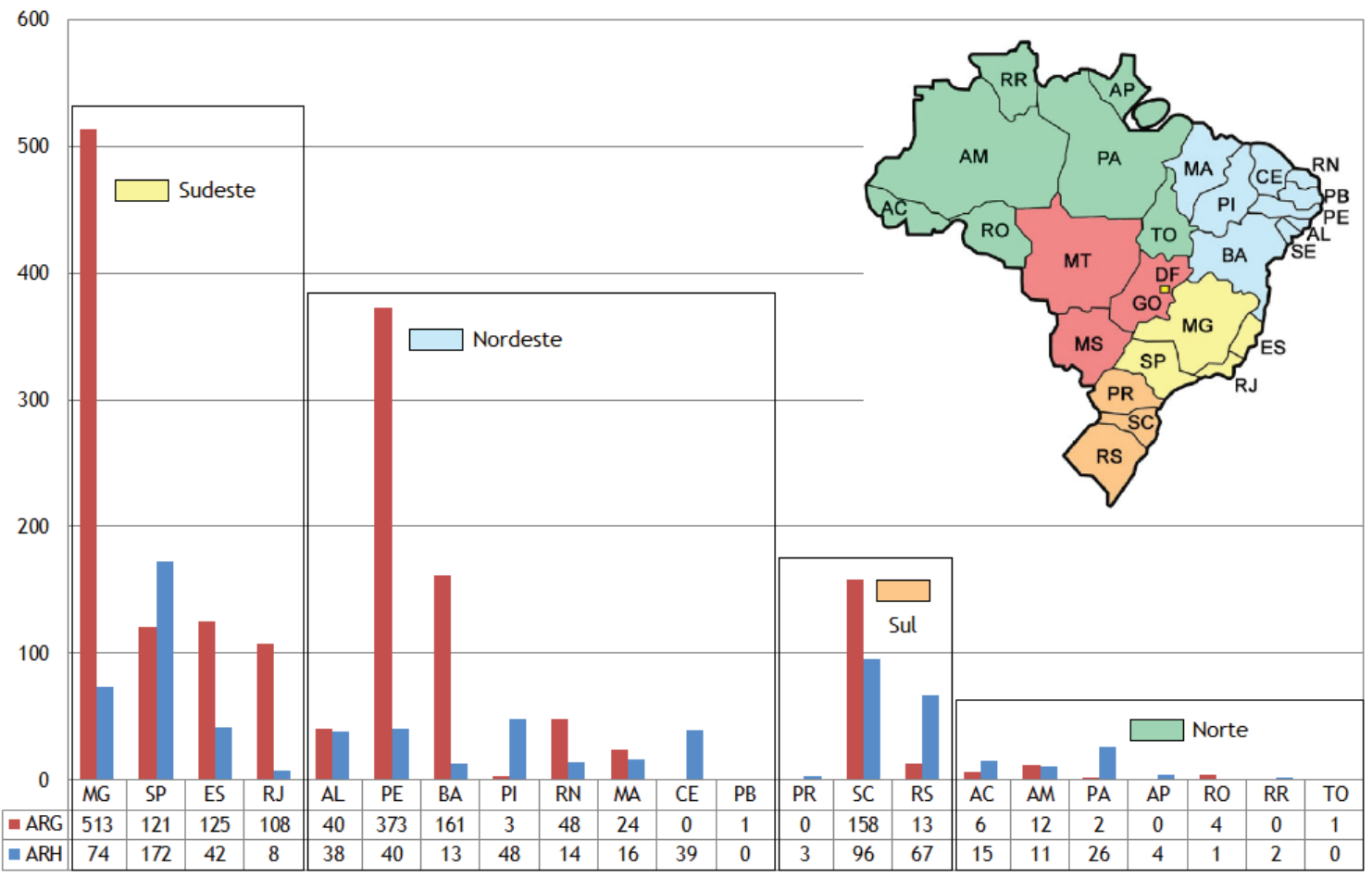

Fig. 3 - Distribuição de escolas localizadas em área de risco no Brasil, classificadas por Estado, por região e por tipologia da ameaça. A barra em vermelho indica o número de escolas em área de risco geológico (ARG). A barra em azul indica o número de escolas em áreas de risco hidrológico (ARH). Diversos estados apresentam escolas em áreas de risco: Acre (AC), Alagoas (AL), Amazonas (AM), Amapá (AP), Bahia (BA), Ceará (CE), Maranhão (MA), Minas Gerais (MG), Pará (PA), Paraíba (PB), Pernambuco (PE), Piauí (PI), Paraná (PR), Rio de Janeiro (RJ), Rio Grande do Norte (RN), Rondônia (RO), Roraima (RR), Rio Grande do Sul (RS), Santa Catarina (SC), São Paulo (SP), Tocantins (TO). As cores no mapa representam as regiões em que estão agrupados os Estados no Brasil.

Fig. 3 - Distribution of Brazilian schools in risk-prone areas, according to the state, region and type of hazard. The red rectangular bar represents the number of schools in landslide prone area $(A R G)$. The blue rectangular bar represents the number of schools in flood-prone areas (ARH). The different colors on the map represent the five regions of Brazil and their states. Brazil's states are: Acre (AC), Alagoas (AL), Amazonas (AM), Amapá (AP), Bahia (BA), Ceará (CE), Maranhão (MA), Minas Gerais (MG), Pará (PA), Paraíba

$(P B)$, Pernambuco (PE), Piauí (PI), Paraná (PR), Rio de Janeiro (RJ), Rio Grande do Norte (RN), Rondônia (RO), Roraima (RR), Rio Grande do Sul (RS), Santa Catarina (SC), São Paulo (SP), Tocantins (TO).

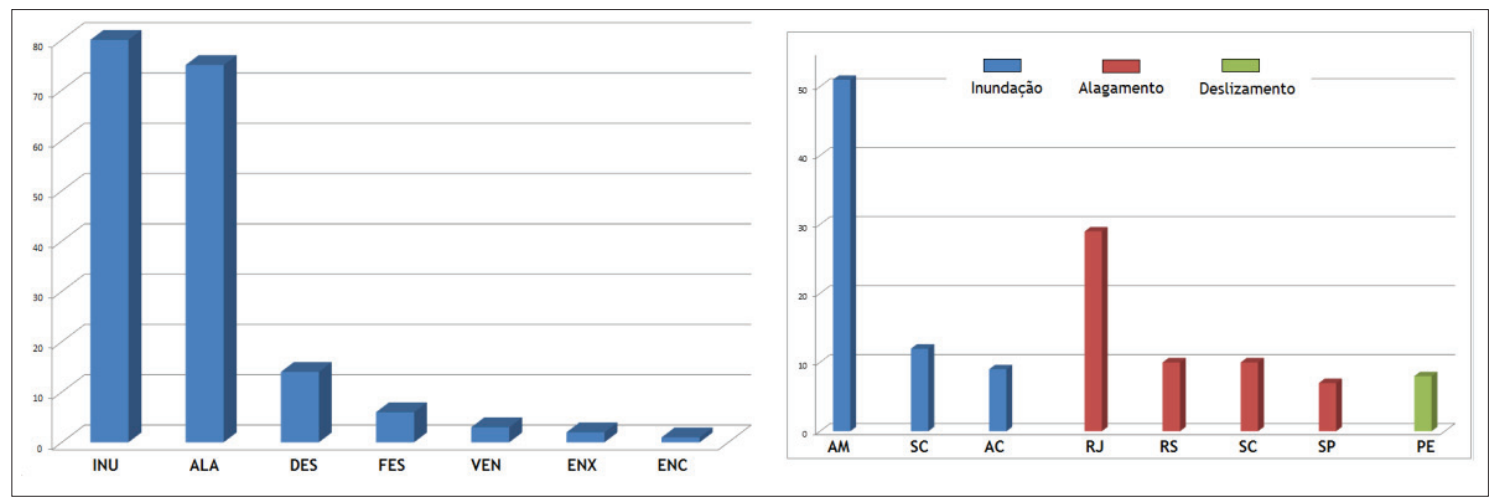

Fig. 4 - Registros jornalísticos sobre escolas afetadas por fenômenos naturais no Brasil, no período de janeiro de 2012 a dezembro de 2015. No gráfico à esquerda apresenta-se o número de escolas afetadas por tipologia de evento: inundações (INU), Alagamentos (ALA), Deslizamentos (DES), Falha estrutural (FES), Vendaval (VEN), Enxurradas (ENX) e Enchentes (ENC); no gráfico à direita apresentam-se os Estados com maior quantidade de escolas afetadas pelos eventos mais frequentes nesse período: Amazonas (AM), Santa Catarina (SC), Acre (AC), Rio de Janeiro (RJ), Rio Grande do Sul (RS), São Paulo (SP), Pernambuco (PE) (Fonte: elaborado pelos autores a partir de pesquisa documental em fontes eletrônicas).

Fig. 4 - Media reports of schools affected by natural hazards in Brazil, from January 2012 to December 2015. On the left (A), the number of schools affected per type of risk: floods (INU), waterlogged (ALA), landslides (DES), structural fault (FES), strong winds (VEN), flashfloods (ENX) and flooding (ENC); on the right (B), the states with the highest number of schools affected by the most frequent natural events in this period: states of Amazonas (AM), Santa Catarina (SC), Acre (AC), Rio de Janeiro (RJ), Rio Grande do Sul (RS), São Paulo (SP), Pernambuco (PE) (Source: elaborated by the authors from documentary research in electronic sources). 
e alagamento) foram mais frequentemente noticiados; destacaram-se, pelo número de escolas afetadas, os Estados do Amazonas, Rio de Janeiro, Santa Catarina, Rio Grande do Sul e Acre. Os eventos geológicos (deslizamentos) foram menos noticiados, destacando-se neste caso Pernambuco.

São numerosos e recorrentes os casos de escolas danificadas e destruídas por fenômenos hidrológicos e geológicos no Brasil. Os conceitos de risco extensivo e intensivo permitem distinguir os desastres em termos da sua frequência (período de recorrência) e intensidade (grau do impacto) (UNISDR, 2015). O risco extensivo relaciona-se com pequenas perdas de alta frequência e baixa intensidade que se manifestam em resolução espacial local (município ou unidade menor). Está associado com a exposição de pequenas populações, geograficamente dispersas, a condições persistentes de ameaças. 0 risco intensivo refere-se a perdas de baixa frequência e alta intensidade que se manifestam em resolução nacional (região, país ou conjunto de países). Está associado com a exposição de grandes populações geograficamente concentradas e muito vulneráveis a eventos de altíssima liberação de energia (Muñoz et al., 2017). Os dados apresentados na fig. 4 são somente uma amostra de eventos extensivos, levantada na mídia com o intuito de identificar padrões na tipologia das ocorrências como, por exemplo, sua distribuição espacial no território brasileiro. Para complementar esta informação foram levantados dados oficiais sobre o impacto nas escolas de três eventos extremos, de caráter intensivo, que se constituíram em tragédia nacional:

1) as inundações no Vale do Itajaí, estado de Santa Catarina, em 2008, que afetaram 270 escolas e comprometeram a continuidade das aulas durante os meses posteriores (Banco Mundial, 2012b);

2) as inundações no Estado Alagoas (2010), com registro de 115 escolas danificadas, 98 da rede municipal e 17 da rede estadual (Banco Mundial, 2010c); e

3) a tragédia da Região Serrana de Rio de Janeiro (2011), em que 14 escolas foram atingidas em Nova Friburgo, cinco em Teresópolis, três em Sumidouro e outras três em Petrópolis, totalizando 25 estabelecimentos atingidos por inundações, deslizamentos e enxurradas (Assembleia Legislativa do Estado do Rio de Janeiro - ALERJ, 2011).

\section{Tipologia dos impactos}

A partir dos dados analisados nesta pesquisa observaramse cinco tipologias de impacto de eventos naturais nas escolas: sobre a integridade física da comunidade escolar, sobre o uso e ocupação da escola, sobre a infraestrutura do edifício escolar, sobre materiais e equipamentos escolares, e sobre o próprio exercício educativo.
Integridade física

As escolas são locais onde crianças e adolescentes passam a maior parte do seu tempo e onde se concentra e transita grande quantidade de pessoas por pelo menos cinco dias da semana. A alta frequência de ocupação e a densidade populacional desses espaços aumenta o grau de vulnerabilidade física das pessoas, entendendo esta vulnerabilidade nos termos de Pavan (2009).

Quando um evento natural ocorre no horário de expediente aumenta a chance de acontecer uma tragédia. Infelizmente isto pode ser constatado a partir de centenas de casos históricos: no terremoto em Armênia, 25 janeiro de 1999, 13:19 (hora local, jornada da tarde), mais de 17 mil estudantes perderam a vida; terremoto em Bhuj (Índia), 26 de janeiro de 2001, 8:46 (hora local, jornada da manhã), 971 estudantes e 31 professores faleceram; terremoto em Cachemira (Paquistão), 8 de outubro de 2005, 8:50 (hora local, jornada da manhã), mais de 19 mil estudantes morreram soterrados pelos escombros das suas escolas (Earthquake Engineering Research Institute, 2006); tufão Durian, 01 de dezembro de 2006, uma escola foi atingida por deslizamentos e 245 pessoas, entre crianças e adultos, foram mortos (Tuladhar et al., 2014).

No Brasil ainda não se têm registros de tragédias desse tipo, mas há sinais de alerta. Citamos alguns exemplos pontuais que ilustram a situação de escolas localizadas em áreas de risco no país: 1) a escola municipal Eliana Lúcia Monteiro, Manaus (AM) exposta a risco de deslizamentos. A medida de prevenção de pais e alunos é cancelar as aulas quando caem fortes chuvas por medo diante do risco iminente: "Cinco alunos da sala da minha filha já saíram de lá por causa disso. A professora orienta os alunos a não sentarem nos fundos da sala quando tem temporal", disse a mãe de uma aluna de sete anos (Neto, 2014); 2) Creche-Escola de Educação Infantil Breno Moacyr Bastos Marson, no município de Franca (SP), exposta à inundação. Já aconteceu um evento (abril de 2014) quando funcionários tiveram que socorrer as crianças que estavam nas salas inundadas (Pimenta, 2014); 3) Escola municipal localizada na cidade de Almirante Tamandaré (PR), exposta a alagamentos. Durante um episódio de alagamento em novembro de 2014, 90 crianças foram protegidas pelos funcionários do local; "sorte que só sofremos danos materiais e que a nossa equipe maravilhosa socorreu todos na hora certa. Nenhuma criança se machucou", disse a diretora da instituição (Sequinel; Nascimento, 2014); 4) escola Deodoro, Concórdia (SC), em 14 de julho de 2015, chuvas intensas causaram o transbordamento do Rio dos Queimados. A Escola Deodoro ficou ilhada e "foi preciso que o Jipe Clube fosse até o local para a retirada dos alunos" (Bortoli, 2014); 5) escola Silvio de Almeida, Promissão (SP), exposta a eventos hidrológicos. 
Em 24 de novembro de 2015, por volta da 13:30 h, esta escola alagou e as crianças ficaram ilhadas por cerca de 20 minutos. Os alunos precisaram subir nos bancos do pátio para se protegerem (fot. 1). 0 diretor da escola relatou a situação de vulnerabilidade: "como a escola fica em uma baixada, a água da chuva passa pelo pátio, salas de aula e até salas da administração [...]alguns pais vieram buscar os filhos mais cedo. Outros alunos ficaram até o horário que encerra as atividades e os professores os levaram para a quadra, que fica em uma parte alta e não estava alagada [...] a outra vez choveu bem mais forte e uma enxurrada destruiu vários documentos de uma sala da administração" (Patriarca, 2015).

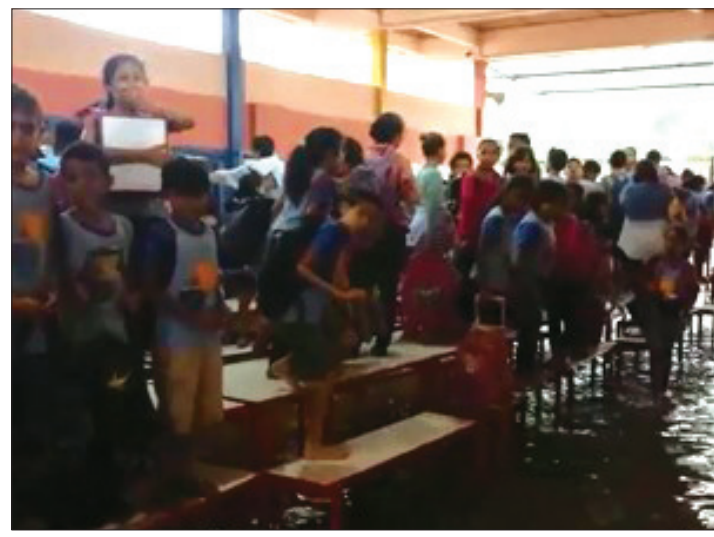

Fot. 1 - Alunos sobem nas cadeiras da sua sala de aula para se proteger durante fortes chuvas que alagaram escola na cidade de Promissão (SP), em 24 de novembro de 2015 (Fonte: Patriarca, 2015).

Photo 1 - Students climb onto the chairs in their classroom to protect themselves during heavy rains that flooded an elementary school in the city of Promissão (SP)

(Source: Patriarca, 2015).

\section{Uso e ocupação da escola}

Em situações de desastre, as escolas costumam ser utilizadas como abrigo. Na teoria, dada sua oferta de infraestrutura e serviços básicos, estes locais deveriam ser ideais para abrigar as pessoas afetadas e facilitar o trabalho das equipes de resgate, de logística humanitária e de governantes. Por outro lado, utilizar as escolas como abrigo tem profundas implicações para a continuidade da formação de crianças e adolescentes, assim como pode colocar em risco sua integridade física e emocional, especialmente diante de processos de estigmatização em que a reivindicação pelo uso do espaço da escola é objeto de conflito entre populações abrigadas e nãoabrigadas (Valencio et al., 2009a; Marchezini, 2014a). Embora de difícil solução, esta dicotomia deve ser abordada nos planos de gestão escolar de risco.

Para ilustrar esta situação em escolas do Brasil, foi feita uma pesquisa no contexto de desastres ocorridos em 20 estados brasileiros (aproximadamente 1200 municípios) entre janeiro e março de 2004. Na ocasião, chuvas deflagraram inundações, deslizamentos e enxurradas que impactaram aproximadamente 1838 escolas públicas municipais e estaduais (fig. 5), das quais 469 (338 municipais) foram ocupadas como abrigos temporários (BRASIL, 2004). Importante salientar que os dados tendem a estar subestimados, uma vez que informações dos estados de Goiás, Minas Gerais, Santa Catarina e São Paulo não estavam disponíveis nas fontes documentais consultadas. Dentre as escolas públicas atingidas - sejam elas danificadas ou utilizadas como abrigo - a maior proporção se encontra nas de nível municipal, com exceção do Estado do Ceará (com 44 escolas municipais e 85 estaduais danificadas; 49 escolas municipais e 22 estaduais utilizadas como abrigo). Os valores nominais também acendem um alerta, como no estado de Pernambuco, que apresentou a maior quantidade de escolas danificadas e/ou utilizadas como abrigo (806 escolas municipais e 156 estaduais danificadas; 30 escolas municipais e 21 estaduais utilizadas como abrigo).

Os dados apresentados na fig. 5 são apenas um indicativo da complexidade das situações de vulnerabilidade das escolas municipais e estaduais frente a desastres no Brasil. São necessárias novas pesquisas para ter informação consolidada de impactos qualitativos e quantitativos sobre o número e condição de famílias abrigadas em relação à capacidade da escola para alojá-las.

Existe uma série de conflitos que podem surgir nos abrigos localizados em escolas, os quais normalmente afetam toda a comunidade escolar, que inclui alunos, professores, famílias e vizinhança. Em junho de 2005, por exemplo, ocorreram inundações que afetaram a cidade de Jaboatão dos Guararapes (PE); na ocasião foi instalado um abrigo temporário na escola do bairro Moenda de Bronze, onde foram alocadas várias famílias que ficaram à espera de uma solução habitacional. Após três meses de permanência nas instalações da escola, a comunidade escolar reivindicou o seu direito de uso pleno da edificação para atender a demanda de educação, e pediu pela realocação dessas famílias em outro lugar, exacerbando desta forma o conflito entre as duas comunidades (Valencio et al., 2009a). Uma situação semelhante foi vivenciada no Vale do Itajaí (SC) em novembro de 2008: na escola Marcos Konder, município de Ilhota, surgiram conflitos permanentes entre a comunidade abrigada e a comunidade escolar pela frequente ameaça de despejo das famílias diante da necessidade de retorno dos alunos às aulas depois das férias de fim do ano (Marchezini, 2014a).

\section{Infraestrutura do edifício escolar}

O fato do edifício da escola ser um lugar estrategicamente usado como abrigo, especialmente quando são escolas da rede pública, não garante a segurança 


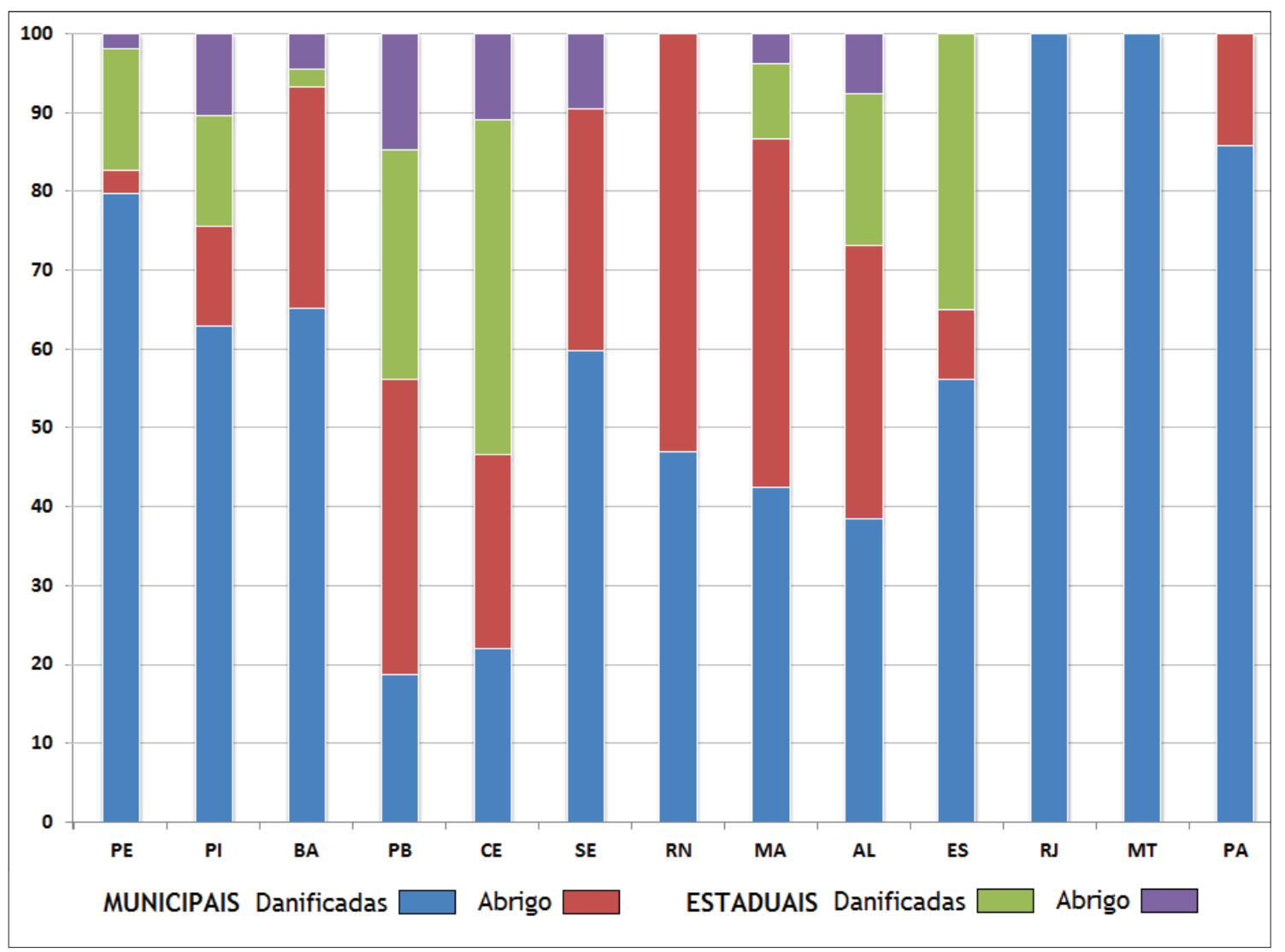

Fig. 5 - Proporção de escolas públicas municipais e estaduais danificadas ou utilizadas como abrigo no primeiro trimestre de 2004, discriminadas por Estado: Pernambuco (PE), Piauí (PI), Bahia (BA), Paraíba (PB), Ceará (CE), Sergipe (SE), Rio Grande do Norte (RN), Maranhão (MA), Alagoas (AL), Espirito Santo (ES), Rio de Janeiro (RJ), Mato Grosso (MT), Pará (PA) foram os estados mais atingidos (Fonte: preparada pelos autores com base em dados de Brasil (2004)).

Fig. 5 - Percentage of municipal and state public schools damaged in disasters or used as temporary shelter in the first quarter of 2004, broken down by state: Pernambuco (State of Pernambuco), Piauí (State of Bahia), Bahia State, Paraiba State, (State of Pará, State of Pará, State of Pará, State of Pará, State of Pará, State of Pará, State of Pará, State of Pará, State of Pará, State of Sergipe, State of Rio Grande do Norte, State of Parana, State of Parana were the most affected during disasters in the first quarter of 2004.

(Source: prepared by the authors based on data from Brazil (2004)).

para as pessoas ali abrigadas. Nas inundações ocorridas em janeiro de 2010 no município de São Luiz do Paraitinga/SP, por exemplo, uma escola municipal foi danificada e outra escola estadual foi destruída. Quando o rio Paraitinga começou a inundar a região do Centro Histórico, muitas pessoas acabaram se abrigando no prédio da Escola Municipal Waldemar Rodrigues, considerado patrimônio histórico. Santos (2015) retrata que a defesa civil municipal já sabia de vários problemas estruturais nesse prédio e pôde retirar todas as pessoas antes que viesse a ruir na inundação. Na outra margem do rio Paraitinga, muitas famílias se abrigaram em uma escola de educação infantil e foram surpreendidas durante a madrugada, quando o rio começou a invadir a escola. As pessoas tiveram que destruir uma parte do teto para escaparem da inundação e se refugiarem no telhado, à espera de socorro (Marchezini, 2014b).

\section{Materiais e equipamentos escolares}

Além do prédio da escola, os eventos naturais impactam os equipamentos, mobília, documentos, assim como materiais de estudo e pertences particulares de cada membro da escola. Em Imperatriz (MA), durante as chuvas de fevereiro de 2014, a inundação dos riachos Bacuri e Capivara atingiu a escola Centro de Ensino Pedro Ferreira de Alencar (da rede estadual), que registrou mais de 100 livros perdidos, além de computadores e documentos administrativos (Cardoso, 2014) (fot. 2a). Em Concórdia (SC), na comunidade Barra do Tigre, enxurradas invadiram a Escola de Educação Básica Dogello Goss que registrou perda de móveis (fot. 2b), eletrodomésticos, documentos, livros e materiais didáticos. "Além de muito trabalho, tem histórias, coisas que a gente perdeu para sempre. Muito documento para lavar, muita coisa para fazer", disse a diretora da escola (Cordeiro, 2015). 
A mobilidade em ônibus escolares também é vulnerável. No dia 9 de outubro de 2012, durante as fortes chuvas que ocorreram na região de Alegrete (RS), um ônibus escolar foi arrastado pela correnteza ao ficar preso na ponte do arroio Capivari, na rodovia RST 507 (Almeida, 2012). Felizmente nessa ocasião o ônibus não estava transportando estudantes, mas esta situação é um alerta aos gestores que se deve considerar a mobilidade escolar na preparação de planos de contingência.

\section{O exercício educativo}

Numa situação de desastre há diversos aspectos que comprometem a viabilidade e continuidade das aulas. Dentre esses aspectos alguns já foram mencionados, como a perda da estrutura física do prédio escolar, sua mudança de uso de escola para abrigo, a perda de mobília e materiais didáticos e o perigo de acesso ao local. Este último item está relacionado com o conceito
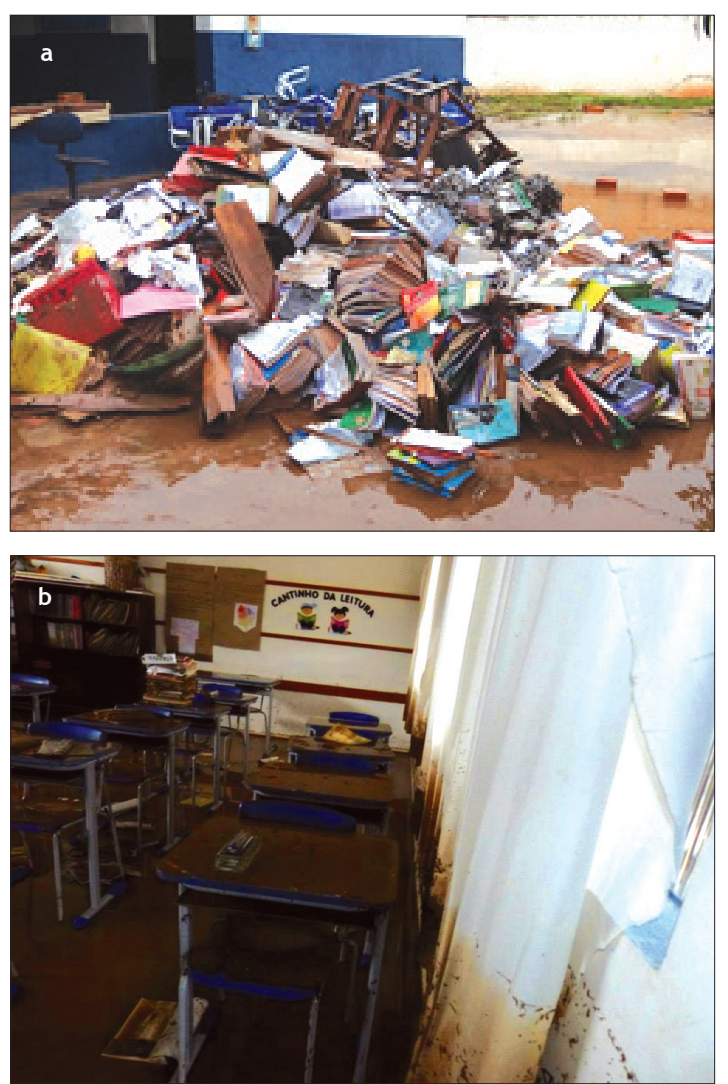

Fot. 2 - Impactos sobre bens das escolas. a) livros encharcados em inundação de escola no município de Imperatriz (MA).

Fotografia: Diana Cardoso (2014); b) cadeiras e mesas enlameadas por inundação em Concórdia, Comunidade Barra do Tigre, (SC) (Fotografia de Rhayana Cordeiro, 2015).

Photo 2 - Impact on school equipment/materials. a) books soaked in flooded school in Imperatriz (MA). Photo: Diana Cardoso (2014); b) chairs and tables coated with mud in flood in Concórdia, Barra do Tigre Community, (SC) (Photography of Rhayana Cordeiro, 2015). de isolamento, que se refere à interrupção do fluxo de alunos, pais, professores e funcionários desde a escola ou em direção a ela, e que pode ter diversas causas, dentre elas alagamentos, quedas de blocos, deslizamentos etc. A magnitude do isolamento está relacionada com a área afetada, e pode ir desde somente um prédio até uma cidade, e com o tempo de duração do fenômeno que pode ir desde horas até vários dias. Os dados levantados para o evento de 2004 apontam para um total de 989 escolas municipais e estaduais isoladas, a maioria delas localizadas em Pernambuco, Bahia e Piauí. Somente no Piauí nove municípios ficaram totalmente isolados (Brasil, 2004). Em Alagoas, durante as inundações de junho de 2010, 115 escolas foram danificadas, onde estudavam aproximadamente 52 mil alunos, sendo cerca de 10 mil na rede estadual e 42 mil na rede municipal (Banco Mundial, 2010c). Em 2015 a inundação do Rio Acre permaneceu por 32 dias (Governo do Acre, 2015). Frente a tais situações, o setor educativo pode optar por estratégias paliativas para reduzir as vulnerabilidades associadas a eventos de lento desenvolvimento, como no caso de inundações graduais. Na região Amazônica, por exemplo, a secretaria municipal de educação do município de Careiro da Várzea (AM) adotou Escolas Flutuantes (fot. 3) para evitar a suspensão das aulas em 12 escolas atingidas (Portal Amazônia, 2014). "Escolas flutuantes" são exemplos de estratégias espontâneas de adaptação visto que estruturas flutuantes já fazem parte da cultura dos ribeirinhos amazônicos.

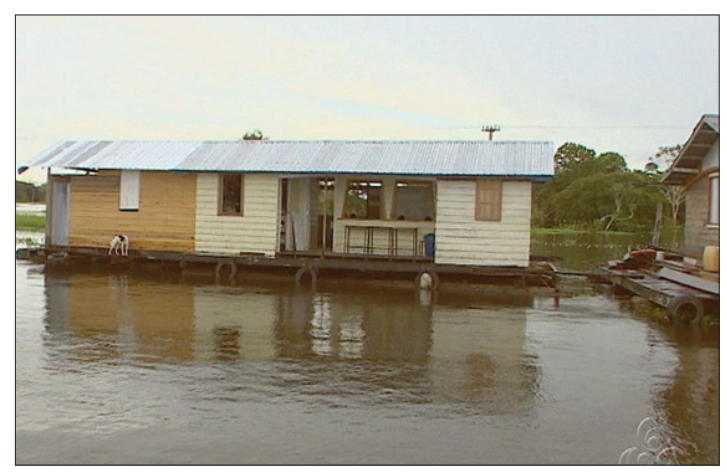

Fot. 3 - Escola flutuante no município Careiro da Várzea (AM), preparada como medida paliativa para dar continuidade às aulas em área inundada (Fonte: Portal Amazônia. Foto TV Amazonas Portal (Portal Amazônia, 2014)).

Photo 3 - Floating school in Careiro da Várzea (AM), prepared as a coping strategy to continue classes during floods

(Source: Portal Amazônia (Photo: TV Amazonas Portal (Portal Amazônia, 2014)).

\section{Considerações sobre a gestão de risco no setor} educativo brasileiro

Para as Nações Unidas, as políticas públicas para gestão de risco de desastres (GRD) nas escolas devem estar fundamentadas em três pilares: 1) instalações seguras 
para a aprendizagem; 2) gestão para a redução de riscos de desastres; e 3) educação para a redução de riscos e fortalecimento da resiliência (Unisdr, 2014). Seguindo essa ordem de ideias apresentamos em seguida alguns desafios no Brasil.

1) Os avanços no sentido de criar instalações seguras ainda são incipientes no Brasil. Entretanto, vale destacar iniciativas como, por exemplo, o projeto de normas de arquitetura da Fundação para o Desenvolvimento da Educação (FDE), responsável pela construção de escolas estaduais em São Paulo. No documento normativo (atualizado em 2011) é indicado que os projetos devem considerar critérios socioambientais como conforto térmico, conforto acústico, plantio de árvores e gramados para contenção de talude ou controle de umidade do solo ou a construção de sistemas de proteção contra descargas atmosféricas. 0 documento exige também a elaboração de um diagnóstico climático preliminar e sugere a utilização de dados meteorológicos de locais com clima equivalente quando não houver dados do local da escola. Como pode ser observado, existe nessa iniciativa a preocupação pela redução da vulnerabilidade estrutural da escola, mas ainda não se consideram aspectos da exposição da escola a fenômenos de origem natural, aspectos estes relacionados à sua localização em relação a ameaças naturais.

2) A GRD no setor educativo envolve a criação de políticas públicas de caráter nacional que viabilizem a criação e implantação de medidas estruturais e não estruturais de gestão de escolas em situação de risco de desastre. Soluções de caráter emergencial podem atender demandas pontuais, como por exemplo, as resoluções $n^{\circ} 22$ e 23 do Fundo Nacional de Desenvolvimento da Educação (FNDE) que, por meio do Programa Especial de Recuperação da Rede Física Escolar Pública, garantiu o repasse de recursos às secretarias de educação dos Estados de Pernambuco e Alagoas impactados por enchentes em 2010. Nesse mesmo sentido, em 2011 o Senado Federal aprovou duas Medidas Provisórias, 530/11 e 531/11 destinadas a recuperar as escolas públicas atingidas por desastres socioambientais; a primeira foi transformada no projeto de lei de conversão (PLV) 20/11 que criou, no âmbito do Ministério da Educação, o plano especial de recuperação da rede física escolar pública, com o objetivo de recuperar as instalações dessas escolas e suas bibliotecas. A segunda abriu crédito extraordinário para a execução do plano (Brasil, 2011; Tribuna Hoje, 2011).

Soluções de longo prazo devem ser consideradas no planejamento do sistema educativo em todos os níveis de governo (nacional, estadual, municipal).
A Lei 12.608 de 10 de abril de 2012, que institui a Política Nacional de Proteção e Defesa Civil PNPDEC, entre outras disposições, no seu artigo 29 acrescenta ao numeral sete do artigo 26 da Lei 9.394, de 20 de dezembro de 1996, que estabelece as diretrizes e bases da educação nacional: "Os currículos do ensino fundamental e médio devem incluir os princípios da proteção e defesa civil e a educação ambiental de forma integrada aos conteúdos obrigatórios". Assim mesmo, as Diretrizes Curriculares Nacionais para Educação Ambiental preconizam "a revisão de práticas escolares fragmentadas [...] e o estabelecimento das relações entre as mudanças do clima e o atual modelo de produção, consumo e organização social, visando à prevenção de desastres ambientais e à proteção das comunidades" (Brasil, 2012). Mais recentemente, o FNDE publicou medidas preventivas no "Roteiro para reformulação de obras - metodologia inovadora para metodologia convencional" (Brasil, 2015, 13), com orientações específicas para a construção de escolas de educação infantil, onde se lê: “É necessário preservar, sempre que possível, as árvores existentes e elaborar um correto escoamento das águas pluviais, por conta dos riscos de deslizamentos e enxurradas". E ressalva que "a observação de diversos fatores, como, por exemplo, a topografia do entorno, permite prever a ocorrência de eventuais acidentes naturais". A situação do pós-impacto consta da Lei Orçamentaria de União/2012 (Brasil, 2012) para a Educação Básica, como assistência financeira para recuperação das redes físicas das escolas públicas estaduais, municipais e do Distrito Federal, afetadas por desastres socioambientais, no sentido de "reconstruir, reformar ou adequar a infraestrutura física predial das escolas e prover outras ações necessárias a garantir a manutenção do atendimento aos alunos das escolas atingidas".

3) Embora o sistema educativo nacional conte com ferramentas legais para a incorporação curricular dos princípios de proteção e defesa civil e da educação ambiental, ainda foi feito pouco nesse sentido no Brasil. Podem ser mencionadas as iniciativas da Defesa Civil e/ou do Corpo de Bombeiros, mas embora bem intencionadas, estas intervenções, além de isoladas e dispersas, revelam um pragmatismo que desconsidera dimensões conceituais e metodológicas ligadas ao currículo da escola. A falta de preocupação com a mediação didático-pedagógica se encontra explicitada no fato do interesse pelo cumprimento da norma mais do que na aplicação de uma metodologia cientifica rigorosa, como pode ser deduzido da seguinte monografia: "todos os órgãos do Sistema Nacional de Defesa Civil (SINDEC) são responsáveis pela disseminação 
da doutrina de proteção civil, cuja finalidade é a redução dos desastres e deveriam ser bem mais enfáticos na divulgação de medidas mitigadoras" (Castanho, 2012).

A gestão para redução de riscos de desastres nas escolas envolve a criação de programas educativos para diminuição da vulnerabilidade, como o desenvolvimento de capacidades para compreensão dos processos naturais da matriz ambiental onde a escola se insere (análise da exposição), bem como o treinamento da comunidade escolar em estratégias de resposta a emergências. Neste último aspecto, o grau de preparação pode-se relacionar à formulação e aplicação de planos de contingência participativos que incluam tanto os diferentes sujeitos da comunidade escolar (professores, funcionários, alunos, pais de alunos etc.) quanto a defesa civil, corpo de bombeiros, comitês de bacias hidrográficas ou outras instituições municipais e membros da sociedade civil. A IV Conferência Nacional Infantojuvenil pelo Meio Ambiente (Brasil, 2013) - "Vamos cuidar do Brasil com escolas sustentáveis" - promoveu uma iniciativa interessante ao inserir, no cadastro de participação a ser respondido pelas escolas, um campo sobre "tipos de riscos", além de solicitar a elaboração de projetos para escolas sustentáveis. Isso permitiu o levantamento de alguns exemplos referentes à percepção de riscos (Trajber, 2014). Uma escola em Alagoas descreveu sua situação de vulnerabilidade física territorial (AL 27218082 - Matriz de Camaragibe):

\section{“[...] em todas as enchentes, nossa escola é uma das primeiras a serem inundadas, deixando toda a escola debaixo d'água, prejudicando assim o ano letivo, danificando materiais escolares e deixando a comunidade próxima à escola em pânico [...] nossa escola está localizada em uma região de risco à saúde e à qualidade de vida de nossos alunos, devido aos roedores que circundam a mesma ser uma região com grande concentração de criatório de animais, em especial de porcos, cavalos, galerias, esgotos e por estar situada em uma localidade baixa que em épocas de chuvas o risco de enchente é iminente. Sem falar que duas lagoas ficam próximas contribuindo assim para a rápida inundação da mesma" (Brasil, 2013).}

O incentivo a relações humanas pautadas na cooperação e no exercício da democracia na escola, em termos do desenvolvimento e execução de estratégias de sustentabilidade socioambiental, e a participação da comunidade escolar são fundamentais nos processos de gestão para redução do risco de desastres. Nesse sentido, a instituição educativa pode incorporar nos seus planos de gestão, práticas de prevenção, mitigação e atenção de desastres desde uma postura aberta que considere todo o seu contexto social, de forma que através dessas práticas a escola e a comunidade possam se fortalecer mutuamente no propósito de reduzir os riscos de desastres socioambientais. Existem experiências científicas sobre o tema de Educação e Redução de Risco de Desastres, através de diferentes metodologias e casos de estudo ao redor do país, como em São Carlos/SP (Valencio et al., 2009b), Niterói/RJ e Jaboatão dos Guararapes/PE (Silva Rosa et al., 2015), na Bacia do Rio Paraitinga/SP (Marchezini e Trajber, 2016; Marchezini et al., 2017); em Angra dos Reis/RJ (Sato et al., 2017), dentre outras experiências ainda não mapeadas. É preciso ir além dos estudos de caso específicos, buscando estrategias para aumentar a escala das escolas envolvidas em políticas públicas de gestão de risco de desastres. 0 diagnóstico apresentado no artigo revela um pouco dos desafios que estão à frente.

\section{Conclusão}

Quanto à distribuição geográfica e exposição das escolas

Os dados apresentados aqui sobre escolas e pessoas expostas a riscos hidrológico e geológico podem estar subestimados, se considerarmos que ainda $83 \%$ dos municípios brasileiros carecem de mapeamento oficial de áreas de risco. No entanto estes resultados são apenas um diagnóstico da situação, e nesse sentido podem ser tidos como indicadores da exposição das escolas no Brasil.

Os resultados permitem identificar as regiões e os Estados com escolas mais expostas às inundações e deslizamentos. Ainda será necessário o levantamento de dados que permitam obter a densidade de escolas e da população expostas, com o objetivo de prever a intensidade do impacto sobre o sistema educativo do país, nos diferentes níveis de governo.

Quanto ao registro histórico de ocorrências de desastres com impacto nas escolas

Em virtude da falta de uma base documental com dados e informações consolidados sobre ocorrências de desastres e impactos nas escolas, neste trabalho optou-se por coletar e sistematizar os dados disponíveis de fontes jornalísticas. Embora esse tipo de dado não seja oficial, ele é válido para fins de diagnóstico, o que atende o objetivo deste estudo.

Da mesma forma que a distribuição territorial de escolas expostas, os dados apresentados neste trabalho permitem observar padrões espaciais na distribuição da tipologia de danos que afetam as escolas no Brasil; embora deduzidos a partir de informação de períodos curtos ou de eventos específicos, esses padrões são indicadores do estado de vulnerabilidade escolar frente a desastres no país. 
Há necessidade de compor bancos de dados de ocorrências em períodos mais longos e com metodologia padronizada para todo o território brasileiro, que permita fazer estudos históricos e prospectivos sobre os impactos de desastres nas escolas de todo o Brasil. Essa metodologia deve considerar tanto questões quantitativas como qualitativas, como por exemplo, a percepção social do risco ou o estigma social para uma escola decorrente do seu uso como abrigo em uma situação de desastre.

\section{Quanto à educação em desastres}

Como destacado já pela Unicef (2008) é fato que crianças que têm conhecimento sobre riscos e ameaças naturais são elementos-chave quando se trata de salvar vidas e proteger os membros da comunidade em momentos de crise. À luz dos dados apresentados neste trabalho revela-se o conjunto de fragilidades do sistema educativo brasileiro frente a riscos de desastres, e demonstra-se a urgência de promover ações educativas de prevenção, alerta e redução do risco de desastres, que envolvam toda a comunidade escolar: alunos, professores, funcionários, pais e vizinhos.

Embora vulneráveis, os diferentes atores desta comunidade não são vítimas passivas, mas podem participar de atividades de preparação para desastres em suas casas, escolas e comunidades. É preciso desenvolver estratégias conjuntas entre o Sistema Nacional de Proteção e Defesa Civil e o sistema educativo, com critério pedagógico na formulação de planos de contingência para as escolas.

\section{Quanto à gestão do risco}

As políticas públicas de prevenção e redução do risco de desastres precisam incorporar dimensões de vulnerabilidade escolar em sua formulação, com vistas a subsidiar a implantação de sistemas de alerta centrados nas pessoas e na redução de sua fragilidade perante desastres. Esta conclusão vem a dar suporte a um dos objetivos da UNISDR (2014), pelo qual se deve "promover uma cultura global de segurança e resiliência através da integração da redução de risco de desastres na componente curricular das escolas, e do continuo envolvimento das crianças e jovens adolescentes nos processos de tomada de decisão para a redução de desastres nas suas comunidades".

\section{Referências bibliográficas}

Anderson, W. (2005). Bringing children into focus on the social science disaster research agenda. International Journal of Mass Emergencies and Disasters, 23,3,159-175. Disponível em: http://www.ijmed.org/articles/376/download/
ASSEMBLEIA LEGISLATIVA DO ESTADO DO RIO DE JANEIRO ALERJ (2011). Relatório e Conclusão da Comissão Parlamentar de Inquérito para investigar as circunstâncias, os fatos, as possíveis omissões, negligências, imprevidências e averiguar possíveis responsabilidades de agentes políticos, públicos e de terceiros, em face do desastre ocorrido nos municípios da região serrana do estado do Rio de Janeiro decorrente das fortes chuvas que causaram inundações e deslizamentos de encostas no período de 11 e 12 de janeiro de 2011. Rio de Janeiro, ALERJ. Disponível em: http://www.luizpaulo.com. br/wp-content/uploads/2015/09/RELAT\%C3\%93RIOFINAL-31-08-11.pdf. Acesso em: 01 abr. 2015.

Almeida, Alair Oliveira (2012, 9 de outubro). Enchente arrasta ônibus escolar e picape em Alegrete. Correio do Povo. Disponível em: http://www.correiodopovo.com. br/Noticias/?Noticia=470978. Acesso em: 27 abr. 2016.

Bortoli, Luan de (2015, 14 de julho). Enchente deixa parte de Concórdia submersa. Rádio Rural. Disponível em: http://www.radiorural.com.br/noticias/17148enchente-em-concordia-acompanhe-em-temporeal-video. Acesso em: 27 abr. 2016.

BANCO MUNDIAL (2012a). Avaliação de perdas e danos: inundações e deslizamentos na Região Serrana do Rio de Janeiro - 2011. Brasília: Banco Mundial. Disponível em:http://www.mi.gov.br/pt/c/document_ library/get_file?uuid=74dde46c-544a-4bc4-a6e1852d4c09be06\&groupld=10157. Acesso em: 27 nov. 2015.

BANCO MUNDIAL (2012b). Avaliação de perdas e danos: inundações bruscas em Santa Catarina - novembro de 2008. Brasília: Banco Mundial. Disponível em: http: //documents. worldbank.org/curated/ en/250881468232500513/pdf/NonAsciiFileName0.pdf. Acesso em: 27 nov. 2015.

BANCO MUNDIAL (2012c). Avaliação de perdas e danos: inundações bruscasemAlagoas- junhode 2010. Brasília: Banco Mundial. Disponível em: http://www.mi.gov. $\mathrm{br} / \mathrm{pt} / \mathrm{c} /$ document_library/get_file?uuid=aecec2155c64-4971-89ee-ed9c6c81 ce40\&groupld=10157. Acesso em: 27 nov. 2015.

BRASIL (2004). Relatório Sala de Situação - Enchentes 2004, SEDEC, Rio de Janeiro.

BRASIL (2011). Escolas terão R\$ $74 \mathrm{mi}$ para estrutura física. Disponível em: http://www.brasil.gov.br/ educacao/2011/04/medida-provisoria-garante-r74-milhoes-para-recuperar-escolas-afetadas-pordesastres . Acesso em: 27 fev. 2016.

BRASIL (2012). Passo a passo para a Conferência de Meio Ambiente na Escola + Educomunicação: escolas sustentáveis. Grácia Lopes, Teresa Melo e Neusa Barbosa - Brasília: Ministério da Educação, 
Secadi: Ministério do Meio Ambiente. http:// conferenciainfanto.mec.gov.br/images/pdf/ cartilha_passoapasso_conf_isbn_final.pdf

BRASIL (2012). Orçamento Federal 2012. Disponível em: www.orcamentofederal.gov.br/orcamentos-anuais/ orcamento-2013-1/.../2030.pdf. Acesso em: 01 out. 2014.

BRASIL (2012). Ministério da Educação. Conselho Nacional de Educação. Resolução n² 2, DE 15 de junho de 2012. Disponível em: http://conferenciainfanto.mec.gov.br/ images/pdf/diretrizes.pdf. Acesso em: 01 jun. 2014.

BRASIL (2015). Ministério da Educação. Fundo Nacional de Desenvolvimento da Educação - FNDE. Roteiro para reformulação de obras - metodologia inovadora para metodologia convencional. Disponível em: http:// www.fnde.gov.br/programas/proinfancia/proinfanciaprojetos-arquitetonicos-para-construcao/proinfanciatipo-1. Acesso em: 25 julho 2016.

Cardoso, D. (2014, 20 de fevereiro). Escola inundada pela chuva perde mais de 100 livros. Portal Imirante. Disponível em: http://imirante.com/imperatriz/noticias/2014/02/20/escola-inundada-pela-chuva-perde-mais-de-100-livros.shtml. Acesso em: 26 abr. 2016.

Castanho, P. A. G. (2012). A gestão do risco de desastres começa na escola: desenvolvendo a percepção de risco através da educação. Monografia (Especialização) Faculdade Metropolitana da Grande Fortaleza, Curso de Especialização em Segurança Pública e Defesa Civil - Fortaleza.

Convery, I., Carroll, B., Balogh, R. (2014). Flooding and schools: experiences in Hull in 2007. Disasters, 39, 1, 146-165. DOI: https://doi.org/10.1111/disa.12091

Cordeiro, R. (2015, 15 de julho). Barra do Tigre se recupera da enchente. Rádio Aliança. Disponível em: http: / /www.radioalianca.com.br/noticia/ materia/id/48543/view/barra-do-tigre-se-recuperada-enchente-video-e-fotos. Acesso em: 27 abr. 2016.

Da Silva-Rosa, T., Mendonça, M. B., Monteiro, T. G., Souza, R. M. de; Lucena, R. (2015). A educação ambiental como estratégia para a redução de riscos socioambientais. Ambiente \& Sociedade (Online), 18, 211-230.

EARTHQUAKE ENGINEERING RESEARCH INSTITUTE (2006). Learning from earthquakes - The Kashmir Earthquake of October 8, 2005: Impacts in Pakistan. Disponível em: https://www.eeri.org/lfe/pdf/kashmir eeri_2nd_report.pdf. Acesso em: 3 de junho 2015.

GOVERNO DO ACRE (2015). Gestão de risco de desastres naturais: preparação e resposta aos eventos extremos no estado do Acre.
Lavell, A. (1993). Ciencias Sociales y Desastres Naturales en America Latina: un encuentro inconcluso. In: Andrew Maskrey (Ed.), Los desastres no son naturales (pp.111-125). Panamá: Red de Estudios Sociales en Prevención de Desastres en América Latina.

Marchezini, V. (2014a). Campos de desabrigados: a continuidade do desastre. São Carlos: Rima Editora.

Marchezini, V. (2014b). Processos de recuperação em desastres: discursos e práticas. São Carlos: Rima Editora.

Marchezini, V. (2015). Redução de vulnerabilidade a desastres: dimensões políticas, científicas e socioeconômicas. WATERLAT-GOBACIT Network Working Papers, 2, 17, 82-102.

Marchezini, V., Wisner, B., Londe, L. de R., Saito, S. M. (2017). Reduction of vulnerability to disasters: from knowledge to action. São Carlos: Rima Editora.

Marchezini, V., Trajber, R.(2016). Youth based learning in disaster risk reduction education: barriers and bridges to promote resilience. In: Michèle Companion, Miriam Chaiken (Eds.), Responses to Disasters and Climate Change: Understanding Vulnerability and Fostering Resilience (pp.27-36).Boca Raton, Flórida, CRC Press, Taylor and Francis Group.

Marchezini, V., Trajber, R., Olivato, D., Muñoz, V. A., Pereira, F. O, Luz, A. E. O. (2017). Participatory Early Warning Systems: Youth, Citizen Science, and Intergenerational Dialogues on Disaster Risk Reduction in Brazil. International Journal of Disaster Risk Science: DOI: https: //doi.org/10.1007/s13753-017-0150-9

Milanez, B., Fonseca, I. F. (2011). Justiça climática e eventos climáticos extremos: uma análise da percepção social no Brasil. Terceiro Incluído. 1, 2, 82 -100.

Muñoz, V. A., Marchezini, V., Santos, L. B. L., Jimenez, N., Velásquez, A. (2017). DesInventar: ferramenta conceitual e plataforma computacional para sistematização de dados e suporte à pesquisa de risco e desastres. In: Marchezini, V, Wisner, B., Londe, L.de R., Saito, S. M. Reduction of vulnerability to disasters: from knowledge to action (pp.311-334) São Carlos: Rima Editora. Disponível em: https://preventionroutes. weebly.com/capiacutetuloschapters.html. Acesso em: 1 dez. 2017.

Neto, O. (2014, 16 de maio). Barranco atrás de escola apresenta risco de deslizamento aos alunos, na Zona Oeste de Manaus. Portal A Crítica. Disponível em: http://acritica. uol.com.br/manaus/Barranco-criancas-Zona-OesteManaus_0_1139286091.html. Acesso em: 28 abr. 2016.

Ochola, S., Eitel, B., Olago, D.(2010). Vulnerability of schools to floods in Nyando River catchment, Kenya. Disasters, 34, 3, 732-754.

DOI: https://doi.org/10.1111/j.1467-7717.2010.01167.x 
O'Keefe, P., Westgate, K., Wisner, B.(1976). Taking the 'Naturalness' Out of 'Natural' Disasters. Nature, 260, 566-567.doi:10.1038/260566a0

Oliver-Smith, A., Alcántara-Ayala, I., Burton, I., Lavell, A. (2016). Forensic investigations of disasters (FORIN): A conceptual framework and guide to research. Beijing: Integrated Research on Disaster Risk.

Oliver-Smith, A., Alcántara-Ayala, I., Burton, I., Lavell, A. (2017). A construção social do risco de desastres: em busca das causas básicas. In: Victor Marchezini, Ben Wisner, Luciana de Resende Londe e Silvia Midori Saito (Eds.), Reduction of Vulnerability to Disasters: from knowledge to action (pp.97-114). São Carlos: Rima Editora. Disponível em: https://preventionroutes.weebly.com/ capiacutetuloschapters.html. Acesso em: 1 dez. 2017.

Patriarca, P. (2015, 25 de novembro). Crianças ficam ilhadas após escola ser inundada durante temporal. Portal G1. Disponível em: http://g1.globo.com/ sp/bauru-marilia/noticia/2015/11/criancas-ficamilhadas-apos-escola-inundar-durante-temporal. html. Acesso em: 26 abr. 2016.

Pavan, B. J. C. (2009). O olhar da criança sobre o desastre: uma análise baseada em desenhos. In: Norma Valencio, Mariana Siena, Victor Marchezini e Juliano Costa Gonçalves (Eds.), Sociologia dos desastres: construção, interfaces e perspectivas no Brasil (pp. 96-106). São Carlos: Rima Editora.

Peek, L. (2008). Children and Disasters: Understanding Vulnerability, Developing Capacities, and Promoting Resilience - An Introduction. Children, Youth and Environments, 18, 1, 1-29.

Pimenta, T. (2014, 12 de abril). Águas da chuva inundam creche recém-inaugurada. Portal GCN.net. Disponível em: http://gcn.net.br/noticias/247449/ franca/2014/04/aguas-da-chuva-inundam-crecherecem-inaugurada. Acesso em: 27 abr. 2016.

PORTAL AMAZÔNIA (2014, 9 de julho). Com cheia, casas flutuantes são usadas como escolas no Amazonas. Portal Amazônia. Disponível em: http://amazonia. org.br/2014/07/com-cheia-casas-flutuantess\%C3\%A3o-usadas-como-escolas-no-amazonas/. Acesso em: 27 abr. 2016.

Romero, G., Maskrey, A. (1993). Como entender los desastres naturales. In: Andrew Maskrey (Ed.), Los desastres no son naturales (pp.6-10). Panamá: Red de Estudios Sociales en Prevención de Desastres en América Latina.

Santos, J. R. C. C. dos (2015). A cultura como protagonista do processo de reconstrução da cidade de São Luiz do Paraitinga/SP (Tese de Doutorado). Universidade de São Paulo.
Sato, A. M., Leal, P. V., da Silva, W. P., Nogueira, I. R., Feitoza, F. da S. B., Santos, F. T., Santos, M. A. de O., Nunes, L. da S., Almeida, J. C., Daniel, P. D. L., Diogo, R. dos S., Oliveira, R. B., Lisboa, V. S., Queirós, A. de C., Araújo, T. E. (2017). Curso de capacitação de professores para redução de desastres. In: Victor Marchezini, Ben Wisner, Luciana de Resende Londe e Silvia Midori Saito (Eds.) Reduction of vulnerability to disasters: from knowledge to action (pp.551-565) São Carlos: Rima Editora. Disponível em: https://preventionroutes. weebly.com/capiacutetuloschapters.html. Acesso em: 1 dez. 2017.

Sequinel, M. Nascimento, A. (2014, 4 de novembro). Creche é inundada durante forte chuva em Almirante Tamandaré. Porta BandaB. Disponível em:http:// www.bandab.com.br/jornalismo/creche-einundada-durante-forte-chuva-em-almirantetamandare/. Acesso em: 26 abr. 2016.

TRIBUNA HOJE (2011, 19 de agosto). Senado Federal trata de plano para recuperar escolas públicas atingidas por enchentes. Jornal Tribuna Hoje. Disponível em: http://www.tribunahoje.com/noticia/3704/ politica/2011/08/19/senado-federal-trata-deplano-para-recuperar-escolas-publicas-atingidaspor-enchentes.html. Acesso em: 25 abr. 2016.

Trajber, R. (2014a). Estudo analítico sobre as políticas públicas de educação com relação às mudanças climáticas, sustentabilidade e prevenção de desastres no Brasil. Relatório Técnico elaborado no âmbito do Projeto 914BRZ2018. São José dos Campos: Unesco/Cemaden/MCTI.

Trajber, R. (2014b). Contribuição para um plano de educação para a redução de impactos de desastres: percepção de riscos, vulnerabilidade socioambiental e construção de uma cultura de sustentabilidade e resiliência. Relatório Técnico elaborado no âmbito do Projeto 914BRZ2018. São José dos Campos: Unesco/Cemaden/MCTI.

Tuladhar, G., Yatabe, R., Dahal, Ranjan K., Bhandary, N. P. (2014). Knowledge of disaster risk reduction among school students in Nepal. Geomatics, Natural Hazards and Risk, 5, 3,190-207.

DOI: https://doi.org/10.1080/19475705.2013.809556

UNITED NATIONS CHILDREN'S FUND-UNICEF (2012). Unicef and Disaster Risk Reduction. Disponível em: http: / / www.unicef.org/malaysia/UNICEF_and_ Disaster_Risk_Reduction.pdf. Acesso em: 6 de junho, 2014

UNITED NATIONS INTERNATIONAL STRATEGY FOR DISASTER REDUCTION-UNISDR (2005). Hyogo Framework for Action 2005-2015: Building the resilience of nations and communities to disasters. United Nations: Geneva. 
UNITED NATIONS INTERNATIONAL STRATEGY FOR DISASTER REDUCTION-UNISDR (2014). Comprehensive school safety framework, A global framework in support of The Global Alliance for Disaster Risk Reduction and Resilience in the Education Sector and The Worldwide Initiative for Safe Schools. Disponível em: http://gadrrres.net/uploads/files/resources/ Comprehensive-School-Safety-Framework-Dec-2014. pdf. Acesso em: 5 jul. 2016.

UNITED NATIONS INTERNATIONAL STRATEGY FOR DISASTER REDUCTION-UNISDR (2015). Sendai Framework for Disaster Risk Reduction 2015-2030. Geneva, Switzerland, 37p. Disponível em: http://www. preventionweb.net/files/43291_sendaiframeworkfordrren. pdf. Acesso em: 6 de julho, 2017.

Valencio, N. F. L. da S. (2012). Para além do dia do desastre: o caso brasileiro. Curitiba: Appris.

Valencio, N. F. L. da S., Siena, M., Pavan, B. J. C., Zago, J. R., Barbosa, A. R.(2006). Implicações éticas e sociopolíticas das práticas de Defesa Civil diante das chuvas: reflexões sobre grupos vulneráveis e cidadania participativa. Revista São Paulo em Perspectiva, 20, 1, 96-108.
Valencio, N. F. L. da S., Marchezini, V., Siena, M. (2009a). Desastre e indife-rença social: o Estado perante os desabrigados. Antropolítica (UFF), 23, 223 - 254.

Valencio, N. F. L. da S., Siena, M., Marchezini, V. (2009b). Maquetes Interativas: fundamentos teóricos, metodológicos e experiências de aplicação. In: Norma Valencio, Mariana Siena, Victor Marchezini, Juliano Costa Gonçalves (Eds.), Sociologia dos Desastres: construção, interfaces e perspectivas no Brasil (pp.199-215). São Carlos/SP: RiMa Editora.

Wilches-Chaux, G. (1993). La vulnerabilidad global. In: Andrew Maskrey (Ed.), Los desastres no son naturales (pp.11-41). Panamá: Red de Estudios Sociales en Prevención de Desastres en América Latina.

Wisner, B.(2006). Let our children teach us! A review of the role of education and knowledge in disaster risk reduction. Geneva: UNISDR.

Wisner, B. (2016). Vulnerability as Concept, Model, Metric, and Tool. Oxford Research Encyclopedia of Natural Hazard Science.

Wisner, B., Blaikie, P., Cannon, T., Davis, I. (2004). At risk: Natural hazards, people's vulnerability, and disasters. London and New York: Routledge. 